\title{
On the Cover: Measurement Layout for Residual Stress Mapping Using
} Slitting

Published online: 28 January 2022

(c) Society for Experimental Mechanics 2022
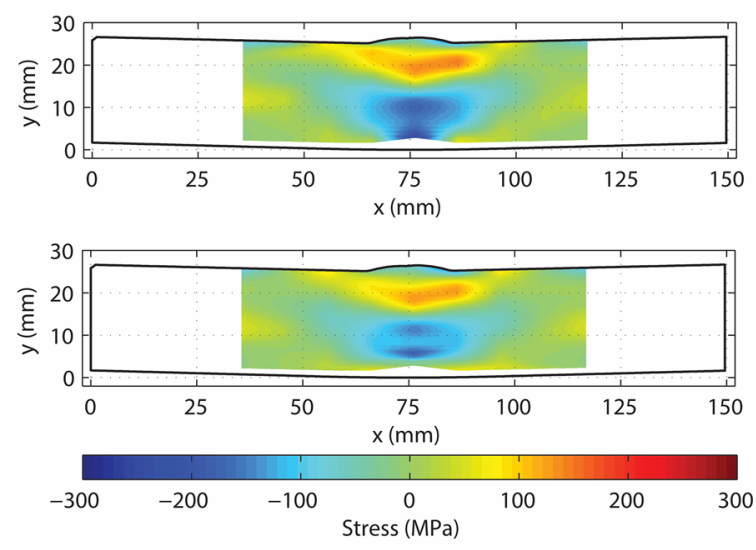

Measurement Layout for Residual Stress Mapping Using Slitting by M. D. Olson, A. T. DeWald, M. R. Hill

Publisher's Note Springer Nature remains neutral with regard to jurisdictional claims in published maps and institutional affiliations. 